\title{
APPLICATION OF INTERVAL ANALYSIS FOR IMPROVING RELIABILITY OF ESTIMATION OF HARDNESS VALUE SPREAD FOR NUCLEAR STRUCTURAL MATERIALS
}

\author{
A.V. Yefimov, T.V. Potanina \\ National Technical University "Kharkiv Polytechnic Institute", Kharkiv, Ukraine \\ E-mail: AVEfimov@kpi.kharkov.ua
}

\begin{abstract}
The applications of the interval and standard probabilistic approaches for verifying the reliability of the results of an experiment studying the mechanical properties of nuclear materials are compared. The presence of "outliers" in a sample of hardness values for hafnium ingots is studied with for fixed oxygen mass content. The situation of measurement error limitation without reliable information about its distribution is considered. The correctness of the application of numerical methods of interval analysis for processing experimental data under conditions of uncertainty and noisy experimental data is shown.
\end{abstract}

\section{INTRODUCTION}

One of the priority tasks in the operation of existing and the creation of new generation nuclear reactors is to ensure safety and increase the resource of regulatory bodies. The solution to this problem can be provided, in particular, through the use of promising structural materials of neutron absorbers. Due to the complex of its physicochemical and mechanical properties, hafnium is such a material [1].

This explains the increased interest to hafnium as an absorbing material for nuclear power reactors in countries with a developed sector of atomic engineering. In particular, for Ukraine this is, firstly, the possibility of a dramatic increase in the service life (up to 30 years) and the reliability of cluster assemblies of the absorbing elements of WWER-1000 reactor protection control systems, which form the basis of Ukrainian nuclear power engineering; secondly, Ukraine has large reserves of zirconium ore, and hafnium production is closely connected with that of zirconium; thirdly, Ukraine has an industrial base for the production of hafnium and its products (sheets, rods, tubes, etc.) [2].

The following methods for producing hafnium have been mastered and implemented on an industrial scale in the world: magnesium thermal reduction of hafnium tetrachloride - the Kroll process (firms in the USA: "Teledine Wah Chang", "Western Zirconium Co"); calcium thermal reduction of hafnium tetrafluoride; electrolytic reduction of potassium hexafluorogaphnate in fluoride chloride melts ("Cezus" (France)).

Today in Ukraine at "Zirconium" State Research and Production Enterprise (Kamyanskoye city), a fundamentally new fluoride calcium-thermal technology for the production of pure hafnium is developed and mastered. Its peculiarity is that hydrometallurgical redistribution in the production of pure hafnium is part of zirconium purification technology. It is characterized by the identity of operations and is distinguished only by the increase in the number of stages of extraction separation. The process of hydrometallurgical redistribution is completed with the preparation of a hafnium fluoride compound - hafnium tetrafluoride
$\left(\mathrm{HfF}_{4}\right)$. The process of calciothermal reduction of hafnium tetrafluoride with subsequent double electron beam melting of the ingots is at the heart of the metallurgical redistribution. The choice of hafnium tetrafluoride as a salt for calciothermal recovery is due to its physical and chemical properties, as well as the possibility of its deep sublimation purification from oxygen $\left(\mathrm{O}_{2}\right)$ and nitrogen $(\mathrm{N})$. Calcium $(\mathrm{Ca})$ hafnium tetrafluoride recovery with the addition of $5 \%$ of iron $(\mathrm{Fe})$ or aluminum $(\mathrm{Al})$ to activate the chemical reaction of recovery allows to obtain compact ingots of hafnium, and electron-beam melting make it possible to clear it completely from many impurities. This scheme allows to obtain hafnium with a total content of hafnium and zirconium which is not less than $99.92 \%$, having a high absorption capacity and suitable for efficient use in nuclear power engineering.

Ukrainian calcium-thermal technology enables to reduce significantly the content of a number of undesirable impurities in hafnium, which affect the plasticity of the metal and its corrosion properties.

Recently, a large amount of research work has been conducted in Ukraine to study the physico-mechanical properties of calcium-thermal hafnium. The Brinell hardness, microhardness, impact strength, micro- and macrostructure have been studied on the samples of cast and deformed calcium-thermal hafnium. Also static tensile tests have been carried out and deformation degree influence on physical properties also has been investigated.

Studies have shown that the deterioration of the mechanical properties of hafnium is significantly affected by gas impurities in it, and especially oxygen. However, due to the fact that hafnium forms strong compounds with oxygen, reducing its concentration in hafnium by means of known methods of removing diatomic gases during electron-beam melting in vacuum is almost impossible.

The increase in purity of hafnium, leads to the decreases of its hardness after electron-beam melting. The process of electron beam remelting consists in melting the initial ingot in vacuum and its subsequent 
crystallization. The main mechanism for refining metals from metal impurities when heated in vacuum is the evaporation of volatile metal impurities. During the remelting process, oxygen and carbon can be purified as a result of the formation and removal of volatile metal oxides having a higher vapor pressure than that of the purified metal.

Each of the above methods for producing pure hafnium has its advantages and disadvantages, and the resulting hafnium ingots have differences in chemical composition within the technical requirements established for each of the methods. The content of some impurities is limited only by maximum values. So, for example, the mass oxygen content for magnesium thermal hafnium ASTM B 7378-84 (USA, Europe) is $0.4 \%$ (grade R-1) and $0.08 \%$ (grade R-2), for iodide hafnium grade GFI-1 GOST 22517-77 (Russia), the actual gas content is within $0.02 \%$, the required oxygen concentration for calcium thermal hafnium grade KTG TU 95.2195-90 (Ukraine) is not more than $0.05 \%$ [3]. In other words, there are uncertainties in the data themselves, which assess the quality of the alloy ingot. And this affects the accuracy of determining the dependences of hardness on the content of impurities, and, particular, oxygen.

It should be noted that such uncertainty is inherent in any process of research and evaluation of experimental data. It contains measurement errors, noise, rounding errors, incompleteness of information, uncertainty caused by methodological errors. It is impossible to overcome the conditions of all these uncertainties, but the analysis of numerous scientific papers on the processing of experimental data shows that one can consider an interval model as one of the most correct models for processing these data [4]. So, in [5], to more accurately determine the relationship between the microhardness of $\mathrm{Zr} 1 \% \mathrm{Nb}$ alloy samples and the content of oxygen in them, subject to the presence of uncertainty in the experimental data, interval analysis methods are applied. Taking this into account, it seems relevant to study the possibility of using interval analysis methods to investigate the hardness values sample of a certain number of hafnium alloys in the presence of "outliers" of observations [6].

\section{INITIAL DATA AND TASK SETTING}

To quantify the effect of oxygen impurities on the mechanical properties of the purified hafnium, in particular the hardness (or microhardness) of the metal, they usually resort to standard statistical methods for processing experimental results. For their application, these approaches need the following crucial assumptions on properties of corruption in the data to be processed [7]:

- the measurement sample is representative and has sufficient length;

- the total error in measurement has a probabilistic character;

- as a rule, probability distributions of the total error are assumed to be Normal;
- there are no chaotic components in measurements;

- errors in sequential measurements are independent.

Unfortunately in practice, a sample of measurements is very short and the errors' probability characteristics are unknown.

In [8], Brinell hardness and chemical composition at the upper and lower ends of hafnium ingots smelted according to the EBR-VAM scheme (electron-beam remelting, vacuum-arc melting) are studied. The measurement results are presented in the Table 1.

It is necessary to process samples of noisy experimental data with a small number of values of the main argument (percentage mass content of oxygen) and multiple measurements in subsamples (hardness of hafnium ingots) for each of its values [9].

The values of the argument are known exactly, and measurements in subsamples contain both ordinary instrumental measurement errors and chaotic distortions (corruptions) of an unknown sign and magnitude. The probabilistic characteristics of both error components are not Normal or unknown; the limitation on the maximum value of the total errors is also uncertain.

Table 1

Experimental data for hafnium ingots

\begin{tabular}{|c|l|}
\hline $\begin{array}{c}\text { Oxygen } \\
\text { content, wt.\% }\end{array}$ & \multicolumn{1}{|c|}{$\begin{array}{c}\text { Brinell hardness of hafnium ingots, } \\
\text { HB }\end{array}$} \\
\hline 0.03 & $172,170,183,176,172,173,171$ \\
\hline 0.04 & $178,176,187,184,180,178,182$, \\
& $185,179,187,182,174,179,177$, \\
& $180,178,178,183,176,198,195$, \\
& $187,196,195$ \\
\hline 0.05 & $194,187,208,188,207,200,193$, \\
& 193,205 \\
\hline
\end{tabular}

\section{RESULTS AND THEIR DISCUSSION}

In the primary processing of experimental data, an important task is to exclude the results of observations obtained as a result of gross errors and outliers. We perform such an analysis for subsamples of the experimental results presented in the Table 1.

A subsample of hardness values with a mass percentage of oxygen of $0.03 \%$ contains $N=7$ observations:

$$
\left\{x_{i}, i=\overline{1,7}\right\}=\{172,170,183,176,172,173,171\} \mathrm{HB} .
$$

We can not guarantee that the observations were carried out with equal accuracy; therefore we will accept the standard instrument error of measurements equal to $5 \%$.

Sets of observational uncertainty:

$$
H_{i}=\left[\underline{h_{i}} ; \bar{h}_{i}\right]=\left[x_{i}-\Delta_{i} ; x_{i}+\Delta_{i}\right],
$$

where $\Delta_{i}$ - absolute error in $i$-observation.

So we get the intervals:

$$
\begin{aligned}
& H_{1}=[163.4 ; 180.6], H_{2}=[161.5 ; 178.5], \\
& H_{3}=[173.85 ; 192.15], H_{4}=[167.2 ; 184.8],
\end{aligned}
$$


$H_{5}=H_{1}=[163.4 ; 180.6], H_{6}=[164.35 ; 181.65]$, $H_{7}=[162.45 ; 179.55]$.

Using the boundaries of the uncertainty sets $H_{i}$, auxiliary extreme values are calculated (for all observations $i=\overline{1, N}$ ):

$$
h_{\min }=\max _{i} \underline{h_{i}}, h_{\max }=\min _{i} \bar{h}_{i} .
$$

These two values are compared: if $h_{\min } \leq h_{\max }$, then sample compatible and the interval $I=\left[h_{\min } ; h_{\max }\right]$ is the actual values interval of the estimated value; if $h_{\min }>h_{\max }$, then sample incompatible.

Accordingly $h_{\min }=173.85, h_{\max }=178.5 \quad$ and subsample is compatible.

Information set $I=[173.85 ; 178.5]$.

Assessment of the central actual value

$$
\begin{aligned}
& x_{c}=\frac{h_{\min }+h_{\max }}{2}, \\
& x_{c}=176.175 .
\end{aligned}
$$

Maximum actual deviation

$$
\begin{gathered}
\Delta x=\frac{h_{\max }-h_{\min }}{2}, \\
\Delta x=2.325 .
\end{gathered}
$$
value

Displacements of observations from the central

$$
\begin{gathered}
\left\{\gamma_{i}=x_{i}-x_{c}, i=\overline{1, N}\right\}, \\
-4.175,-6.175,6.825,-0.175, \\
-4.175,-3.175,-5.175 .
\end{gathered}
$$

Minimum error limit

$$
\begin{aligned}
\Delta_{\text {max }}^{*} & =\frac{x_{\max }-x_{\min }}{2}, \\
\Delta_{\text {max }}^{*} & =6.5 .
\end{aligned}
$$

Limit value of the estimated value

$$
\begin{aligned}
& x^{*}=\frac{x_{\min }+x_{\max }}{2}, \\
& x^{*}=176.5 .
\end{aligned}
$$

We now apply standard statistical methods for processing a subsample. Such an application is formal, since the probabilistic characteristics of the observation error are unknown.

Sample mean

$$
\bar{x}=\frac{\sum_{i} x_{i}}{N}=173.857 .
$$

Standard deviation

$$
\sigma=\sqrt{\left[\sum_{i}\left(x_{i}-\bar{x}\right)^{2}\right] /[N-1]}=4.45 .
$$

Displacements of observations from the sample mean

$$
\begin{aligned}
& -1.86,-3.86,9.14,2.14 \\
& -1.86,-0.86,-2.86
\end{aligned}
$$

Despite the fact that the sample mean belongs to the information set $I=[173.85 ; 178.5]$, it is located almost on its border. The standard deviation is almost two times the maximum actual deviation: $\sigma \approx 1,7 \cdot \Delta x$.

The confidence interval

$$
[\bar{x}-2 \sigma ; \bar{x}+2 \sigma]=[164.957 ; 182.757]
$$

significantly exceeds the interval of the actual values of the estimated value.

The formal application of " $2 \sigma$-rule" to detect a outlier leads to the incorrect removal of a reliable observation 3, since the displacement 9.14 exceeds $2 \sigma$. But the truncated sample without observation number 3 turns out to be biased: the average sample becomes equal to $\bar{x}=172.3$ and does not belong to the information set $I=[173.85 ; 178.5]$.

Consider the subsample of hardness values with a mass percentage of oxygen equal $0.05 \%$. This sample consists of nine observations:

$$
\begin{aligned}
\left\{x_{i}, i=\right. & \overline{1,9}\}= \\
& =\{194,187,208,188,207, \\
& 200,193,193,205\} \mathrm{HB} .
\end{aligned}
$$

We find the boundaries of the uncertainty sets $H_{i}$ and extreme values $h_{\min }, h_{\max }$ by the formulas (1)-(2): $H_{1}=[184.3 ; 203.7], H_{2}=[177.65 ; 196.35]$, $H_{3}=[197.6 ; 218.4], H_{4}=[178.6 ; 197.4]$, $H_{5}=[196.65 ; 217.35], H_{6}=[190.0 ; 210.0]$, $H_{7}=H_{8}=[183.35 ; 202.65], H_{6}=[194.75 ; 215.25]$;

$$
h_{\text {min }}=197.6, h_{\max }=196.35 \text {. }
$$

Since $h_{\min }>h_{\max }$, the subsample incompatible. Additional sample analysis needed.

The procedure for finding single outliers:

1. The set of pairwise intersections of all sets $H_{i}$ and $H_{j}$ is calculated

$$
P_{i j}=H_{i} \cap H_{j}, i=\overline{1, N-1}, j=\overline{i+1, N},
$$

the boundaries of the set $P_{i j}$

$$
\underline{p_{i j}}=\max \left\{\underline{h_{i}}, \underline{h_{j}}\right\}, \overline{p_{i j}}=\min \left\{\overline{h_{i}}, \overline{h_{j}}\right\} .
$$

2. If $p_{i j}>\overline{p_{i j}}$, then $P_{i j}=\varnothing$ and compatibility attribute value $S_{i j}=0$.

If $\underline{p_{i j}} \leq \overline{p_{i j}}$, then $P_{i j} \neq \varnothing$ and compatibility attribute value $S_{i j}=1$.

3. Building a compatibility table

$$
\left\{S_{i j}, S_{i j}=S_{j i}\right\}, i=\overline{1, N-1}, j=\overline{i+1, N} .
$$

4. Observation number $i$ is a single outlier and is deleted if its row in the compatibility table consists of zeros. Single outliers are deleted and the sample is truncated. 
Next, using the compatibility table, we determine the compatible subsample of the maximum length.

The row $m$ (or rows $m_{1}, \ldots, m_{l}$ ) with the maximum number of units is selected: columns $j_{1}, \ldots, j_{k}$. The first of the columns $j_{1}$ with a single value of the compatibility attribute is taken. All column elements are viewed from top to bottom. Elements with $S_{i j}=0$ are deleted from the sequence $j_{1}, \ldots, j_{k}$. The operation is repeated for all columns. We get a set of observation numbers that make up a compatible subsample of the maximum length.

The compatibility Table 2 for this subsample is as follows (taken into account that $x_{7}=x_{8}$ ).

Table 2

Attributes of pairwise compatibility of uncertainty sets

\begin{tabular}{|l|c|c|c|c|c|c|c|c|}
\hline $\mathbf{i} / \mathbf{j}$ & $\mathbf{1}$ & $\mathbf{2}$ & $\mathbf{3}$ & $\mathbf{4}$ & $\mathbf{5}$ & $\mathbf{6}$ & $\mathbf{7}$ & $\mathbf{8}$ \\
\hline $\mathbf{1}$ & & 1 & 1 & 1 & 1 & 1 & 1 & 1 \\
\hline $\mathbf{2}$ & 1 & & 0 & 1 & 0 & 1 & 1 & 1 \\
\hline $\mathbf{3}$ & 1 & 0 & & 0 & 1 & 1 & 1 & 1 \\
\hline $\mathbf{4}$ & 1 & 1 & 0 & & 1 & 1 & 1 & 1 \\
\hline $\mathbf{5}$ & 1 & 0 & 1 & 1 & & 1 & 1 & 1 \\
\hline $\mathbf{6}$ & 1 & 1 & 1 & 1 & 1 & & 1 & 1 \\
\hline $\mathbf{7}$ & 1 & 1 & 1 & 1 & 1 & 1 & & 1 \\
\hline $\mathbf{8}$ & 1 & 1 & 1 & 1 & 1 & 1 & 1 & \\
\hline
\end{tabular}

Trivial cells located on the main diagonal of the table do not participate in the analysis of sample compatibility.

There are no null rows in the Table 2 . Therefore, the sample does not contain single outliers.

Using this algorithm, we got a compatible subsample of the maximum length: observations $1,2,4$, 6, 7, 8. For this sample:

$h_{\text {min }}=194.75, h_{\max }=196.35$, i.e. $h_{\text {min }} \leq h_{\max }$ and sample is compatible.

Information set: $I=[194.75 ; 196.35]$. Assessment of the central actual value: $x_{c}=195.5$. Maximum actual deviation: $\Delta x=0.8$. Displacements of observations from the central value: $-1.5,-8.5,-7.5,4.5,-2.5,9.5$.

According to standard statistical ratios: $\bar{x}=194.5$. This rating is not compatible with the information set: $\bar{x} \notin I=[194.75 ; 196.35]$.

The considered examples show that with a short sample of experimental data and with extreme observation errors, a technique based on the principles of interval analysis gives better accuracy indicators than a standard statistical technique. As well as calculated estimates of the actual value of hardness and uncertainty indicators of experimental data, it is possible to maintain reliable observations in a situation where, according to standard statistical methods, the sample must be truncated.

\section{CONCLUSIONS}

The use of interval analysis methods provides an alternative flexible tool for obtaining a more accurate and complete analysis of experimental data in the presence of incomplete information, noise, outliers measurements, which is typical when conducting studies of the hardness of refined hafnium ingots.

\section{REFERENCES}

1. N.N. Pylypenko. Construction materials for the elements of equipment of nuclear power plants // "Bulletin of Kharkov University”. Physical series “Nuclei, particles, fields”. 2009, N 859, p. 44-50.

2. O.V. Yefimov, M.M. Pylypenko. Constructions, materials, processes and calculations of NPP reactors and steam generators. Kharkiv: "Pidruchnyk NTU "KhPI", 2010, 268 p.

3. G.A. Kolobov, V.V. Pavlov, A.V. Karpenko, A.G. Kolobova. Refining refractory rare metals of group IV of the periodic table // Novi materialy i tekhnolohiyi $v$ metalurhiyi ta mashynobuduvanni. 2015, N 1, p. 89-95 (in Ukrainian).

4. R.E. Moore, R.B. Kearfott, M.J. Cloud. Introduction to interval analysis. Society for Industrial and Applied Mathematics, Philadelphia, 2009, 223 p.

5. A.V. Yefimov, M.M. Pylypenko, T.V. Potanina, et al. Processing of experimental data of the process of refining nuclear material $\mathrm{Zr} 1 \% \mathrm{Nb}$ by electron-beam melting by means of interval analysis methods // Problems of Atomic Science and Technology. Series "Physics of Radiation Effect and Radiation Materials Science”. 2019, N 5, p. 118-123.

6. S.I. Zhilin. Simple method for outlier detection in fitting experimental data under interval error // Chemometrics and Intelligent laboratory System. 2007, N 88(1), p. 60-68.

7. S.I. Kumkov, Yu.V. Mikushina. Interval Approach to Identification of Catalytic Process Parameters // Realible Computing. 2013, N 19(2), p. 197-214.

8. N.K. Filatova. Scientific substantiation of the optimal parameters of industrial technology for the production of hafnium ingots for the nuclear industry: Doctoral thesis. M., 2016, 157 p.

9. S.I. Kumkov. Interval approach to processing noisy experimental data with multiple measurements under conditions of uncertainty // International Conference "Contemporary Problems of Applied Mathematics and Mechanics: Theory, Experiment, and Practice”, 2011. 


\section{ПРИМЕНЕНИЕ ИНТЕРВАЛЬНОГО АНАЛИЗА ДЛЯ ПОВЫШЕНИЯ ДОСТОВЕРНОСТИ ОЦЕНКИ РАЗБРОСА ЗНАЧЕНИЙ ТВЕРДОСТИ ЯДЕРНЫХ КОНСТРУКЦИОННЫХ МАТЕРИАЛОВ}

\section{А.В. Ефимов, Т.В. Потанина}

Проведен сравнительный анализ применения интервального и стандартного вероятностного подходов для проверки достоверности результатов эксперимента по изучению механических свойств ядерных материалов. Исследуется выборка значений твердости образцов слитков гафния при одинаковом массовом содержании кислорода на наличие промахов наблюдений. Рассматривается ситуация ограниченности погрешности измерений без достоверной информации о ее распределении. Показана корректность применения численных методов интервального анализа для обработки экспериментальных данных в условиях неопределенности и зашумленности экспериментальных данных.

\section{ЗАСТОСУВАННЯ ІНТЕРВАЛЬНОГО АНАЛІЗУ ДЛЯ ПІДВИЩЕННЯ ДОСТОВІРНОСТІ ОЦІНКИ РОЗСІЯННЯ ЗНАЧЕНЬ ТВЕРДОСТІ ЯДЕРНИХ КОНСТРУКЦІЙНИХ МАТЕРІАЛІВ}

\section{О.В. Сфімов, Т.В. Потаніна}

Проведено порівняльний аналіз застосування інтервального і стандартного ймовірнісного підходів для перевірки достовірності результатів експерименту з вивчення механічних властивостей ядерних матеріалів. Досліджується вибірка значень твердості зразків злитків гафнію при однаковому масовому вмісті кисню на наявність промахів спостережень. Розглядається ситуація обмеженості похибки вимірювань без достовірної інформації про іiі розподіл. Показана коректність застосування чисельних методів інтервального аналізу для обробки експериментальних даних в умовах невизначеності і наявності «шуму» в експериментальних даних. 